\title{
Research Situation and Existing Problems of the Direction Reduction Process for Utilizing Vanadium Bearing Titano-magnetite
}

\author{
Gong-Guo LIU ${ }^{\mathrm{a}}$, Yong-Cai WEN ${ }^{\mathrm{b}}$, Jie QIN ${ }^{*}$
}

\author{
Pangang Group Research Institute Co., Ltd., State Key Laboratory for Vanadium Titanium \\ Resources Comprehensive Utilization, Panzhihua 617000, China \\ acquart2@126.com, b32062385@qq.com, 'cqinjie110110@126.com \\ ${ }^{*}$ Corresponding author
}

Keywords: Vanadium Bearing Titanomagnetite, Direct Reduction, Comprehensive Utilization, Research.

\begin{abstract}
A pilot plant for comprehensive utilization of the vanadium titanium magnetite resources was constructedin Pangang Group, and the plant applies direction reduction in the rotary hearth furnace (RHF)-melting deep reduction in electric arc furnace (EAF) as the main process. Through constant experimental research, optimization and improvement many technical problems have been solved such as parameters controlling of the RHF, recovering vanadium slag from the hot metal with low carbon and high silicon content, recovering $\mathrm{V}_{2} \mathrm{O}_{5}$ from vanadium slag with high $\mathrm{SiO}_{2}$ content, producing titanium pigment from the titanium slag, etc. This process is feasible and the recovery rate of $\mathrm{Fe}, \mathrm{V}$, and Ti reach to $89 \%, 45 \%$, and $72 \%$ respectively. On the other hand, there exist some problems that have not been solved yet including short life span of the refractory of the EAF, low recovery rate of the thermal energy and so on. Under current conditions, deep researches are need to be done continuously and study on the shaft furnace should be carried out to make useful supplement for the RHF direct reduction process.
\end{abstract}

\section{Introduction}

There are large reserves of vanadium titanium resources in Pan-xi area, Fe, V, Ti and some other elements combine with each and form the vanadium bearing titanomagnetite. At present, Pangang Group applies BF-BOF process to smelt the magnetite and becomes the world leader for utilizing the vanadium bearing titanomagnetite. However, the BF-BOF process just recovers Fe and $\mathrm{V}$ from the iron ore, Ti stays in the titanium slag and there is no efficient method to separate it from the slag [1].

In recent years, the rotary hearth furnace (RHF) direct reduction process is developing rapidly. Some enterprises such as Sha steel and Rizhao steel use it to dispose the wastes of the steel plants $[2,3]$. Based on the characteristics of the vanadium titanium resources and large amount of experiments, Pangang constructed the 100,000/tpy vanadium bearing titanomagnetite comprehensive utilization pilot plant in 2010 and the plant applied RHF direct reduction-EAF melting and deep reduction process. Through carrying out experiments data could be obtained and make supporting for the developing of technologies and the large scale production.

Currently, the plant can meet the demand of carrying out experiments via continuous optimization and some technical parameters reach to the design values. But there is no denying that there are some difficult problems existing in the process and deep research need to be done continuously.

\section{Research Status of the Vanadium Bearing Titanomagnetite Direct Reduction Process}

\section{Technical Indexes}

Under steady operation conditions, recover rate of $\mathrm{Fe}, \mathrm{V}$ and $\mathrm{Ti}$ could reach to $89 \%, 45 \%$ and $72 \%$ respectively. The operation indexes of the comprehensive utilization pilot plant are shown in table 1 
Tab. 1 Main technical indexes of the pilot plant

\begin{tabular}{ccc}
\hline Items & Design index & Production index \\
\hline Granulation rate//\% & 85 & $80-85$ \\
Metallization rate//\% & 85 & $70-85$ \\
Energy consumption/t DRI /(GJ) & 15 & 13.6 \\
Power consumption/t DRI /(kWh) & 800 & $\geq 970$ \\
Grade of titanium slag//\% & $>46$ & $43-46$ \\
Grade of vanadium slag/\% & $6-8$ & $\geq 10$ \\
\hline
\end{tabular}

It can been seen from table 1 that among main technical indexes, the power consumption and titanium slag grade have room to be improved.

\section{General Situation of the Experiments and Production}

Technology and equipment of the raw material system and RHF direct reduction system

Research has been carried out to ensure high metallization rate. Superior parameters have been formulated via repeated trials. Average metallization rate reaches to $75 \%$ and the highest value is 95\%. Though the average lever does not achieve the design index, it could meet the demand of the operation of the plant. Besides, the energy consumption for per ton DRI is 13.6GJ which is lower than the design index (15GJ).

Researches have been done to prevent the re-oxidation of the metallized pellets storing in tanks and bins and measures have been tested to choose the better one. The re-oxidation rate can be controlled below 5\% via applying the protective measures and the problem of bonding of the metallized pellets was solved at the same time.

Charging and discharging devices of RHF have been improved according to the production situation and the pellets can be distributed on the bed of the furnace uniformly and discharged out of the furnace completely. The waste heat utilization system of RHF is creative and part of the exhaust gas is used to dry iron ore concentrate and part to dry the carbon-bearing pellets. This system makes full use of the high temperature waste gas produced by RHF and operates smoothly in real production.

\section{Technology and Equipment Research on the Separating Process of Slag and Hot Metal in EAF}

Tests prove that smelting metallized pellets in the EAF and promoting V coming into hot metal at the same time is the most difficult part in the direct reduction-melting and deep reduction process. Now, basic operating system of the EAF procedure has been formulated, the average vanadium reduction rate reaches to over $80 \%$ and the $\mathrm{TiO}_{2}$ content in the titanium slag rises to $43 \% \sim 46 \%$ gradually. However, for some key indexes, there is a certain gap with the design value such as power consumption of each ton pellet and life span of the EAF lining, etc.

Works of promoting vanadium coming into hot metal and preventing silicon and titanium coming into hot metal at the same time have been done. At present, vanadium reduction rate reaches to the design value under conditions of controlling the silicon content in hot metal below certain value. Metallic iron content $(\mathrm{MFe})$ in the titanium slag is below $1.2 \%$ which is better than the design value $(<2.5 \%)$.

Hearth structure of the EAF has been optimized and slag separates from hot metal smoothly. On the other hand, in order to produce qualified titanium slag with high $\mathrm{TiO}_{2}$ content there is no slag adjusting measures applied in this process which leads to low carbon content $(\leq 2.5 \%)$ in the hot metal. Low carbon content of hot metal causes adverse effects for the vanadium recovery and semi-steel ingot procedures.

\section{Researches on the Technologies of Vanadium and Titanium Recovery}

In the EAF procedure, measures of promoting vanadium and preventing silicon have been applied which can make sure of the slag quality. For the vanadium slag, vanadium recovery 
technologies and new process have been developed, $\mathrm{V}_{2} \mathrm{O}_{5}$ products of grade 99 that meeting the demand of standard GB3283-87 have been produced and the recovery rate of the vanadium extraction procedure is more than $80 \%$.

All of the titanium dioxide products reach to the R258 lever under certain condition, average recovery rate of $\mathrm{TiO}_{2}$ is $82.10 \%$. Besides, Pangang Group has carried out experiments to purify the titanium slag and the $\mathrm{TiO}_{2}$ content can be improved to $63 \%$ 69\% and the titanium recovery may reach to $70 \%$.

\section{Key Technologies of the Process}

\section{Technologies of Vanadium Bearing Titanomagnetite Direct Reduction in RHF}

Parameters like $\mathrm{C} / \mathrm{O}$ in carbon bearing pellets, reduction temperature, reduction atmosphere, bed depth of RHF have been optimized through repeating experiments, and they can be adjusted flexibly via changing the pressure and flow rate of the coal gas, combustion air and exhaust gas, so the metallization rate of the metallized pellets can be controlled in a certain range to meet the need of experiments. At the same time, technologies of controlling bed rising of RHF and preventing re-oxidation of the metallized pellets have been studied and efficient measures have been applied to solve these problems.

\section{Technologies of Producing Vanadium Slag from Low Carbon Content Hot Metal}

In this process, oxygen is blew into hot metal and the $\mathrm{V}$ element will be oxidized into $\mathrm{V}_{2} \mathrm{O}_{3}$ or $\mathrm{V}_{2} \mathrm{O}_{5}$, at the same time, other elements like $\mathrm{C}, \mathrm{Fe}, \mathrm{Si}$, Ti etc. are oxidized into relevant oxides, so the vanadium slag forms. As we all know, temperature should be controlled at a low lever to avoid the extra oxidation of carbon element, however, the hot metal produced by EAF has the feature of low carbon content and the liquidus is higher than that of the common hot metal produced by blast furnace. So the reaction conditions in the pilot plant are worse than that of the converter. Hot metal cooling system has been established and optimized constantly to maintain the temperature within suitable range and qualified vanadium slag has been produced successfully. Furthermore, technologies of extracting vanadium from the slag and producing $\mathrm{V}_{2} \mathrm{O}_{5}$ products of grade 99 that meet the demands of standard GB3283-87have been developed successfully as well.

\section{Technologies of Producing Titanium Pigment by the High Impurity Content Titanium Slag}

The $\mathrm{TiO}_{2}$ content of the titanium slag produced by EAF in the pilot plant reaches to around $46 \%$, and the rests are impurities including $\mathrm{SiO}_{2}, \mathrm{MgO}$, and $\mathrm{Al}_{2} \mathrm{O}_{3}$ etc. Research has been carried out by means of experiments and key technologies formed in this process such as improving acidolysis rate of the titanium slag, improving quality of metatitanic acid and optimizing parameters of the salt treatment and calcination procedures, etc. The titanium dioxide products reach to the R258 lever and the average recovery rate of $\mathrm{TiO}_{2}$ is $82.10 \%$.

\section{Analyses of Restrictive Problems}

Practices of running the plant show that applying the process of direction reduction in RHF-melting and deep reduction in EAF to treat the vanadium bearing titanomagnetite is doable in technical aspect, however, there are some restrictive problems existing in the real production that have not been solved and we need to overcome them and put this process into large scale production.

\section{Problem of Short Life Span of EAF Lining}

Metallized pellets melt and the slag separates from the hot metal in EAF. In order to reduce impurity amounts there is nothing else put into the molten bath except moderate reductant, so the titanium slag is a typical acid slag and the binary basicity is about 0.3. It is difficult to choose materials of the EAF lining under these conditions, on the one hand, conventional acid refractories can meet the demands of refractoriness and thermal shock resistance, on the other hand, basic 
refractories do not have high anti-erosion abilities when smelting acid slag and refractories eroded into the slag will reduce $\mathrm{TiO}_{2}$ content of the titanium slag.

Choosing refractories of the EAF for smelting vanadium bearing titanomagnetite metallized pellets is important, and it has significant effects on the lining life, smelting process and cost of the products. Pangang cooperates with relevant college and develops a new type refractory material which gets good results in laboratory experiments and the using effect should be tested in the production of the pilot plant.

\section{Problem of Recycling the Heat Energy}

For the blast furnace, most mass and heat transfer happens in the inside of the furnace, large amount of gases generating in the hearth exchange heat efficiently with the materials, then the gases are used to generate power (TRT) and finally applied as fuel. Comparing with blast furnace process, the non-blast furnace process has lower heat recovery rate. Take the pilot plant as an example, the RHF produces large amount $\left(27 \mathrm{kNm}^{3} / \mathrm{h}\right)$ of waste gases with temperature about $650^{\circ} \mathrm{C}$, for the EAF, gas amount is fluctuant during different smelting period, gas flow is about $100 \sim 160 \mathrm{kNm}^{3} / \mathrm{h}$ and the temperature is about $140 \sim 220^{\circ} \mathrm{C}$. These gases are not fully used except drying raw materials and huge loss of heat energy occurs. Most plants applying RHF process at home and abroad have the same problem and it must be solved if we want to develop this process.

\section{Problem of Using the Titanium Slag}

$\mathrm{TiO}_{2}$ content in the titanium slag produce by the pilot plant is around $46 \%$, which is higher than the value of blast furnace slag (23\%). But, research results we have got show that it is difficult to use this kind of titanium slag in a large scale. Now the main way is applying the slag as material of the sulfate process to produce titanium dioxide products. Experimental results show that the slag should be mixed with other materials with proper ratio of $30 \% \sim 60 \%$, that means for keeping high quality of the titanium dioxide produces the slag should not be used as the material of sulfate process solely.

Sulfate process is a method to use the titanium slag and it should be further studied to optimize the parameters. At the same time, other processes should be researched, and many works have been done already, for instance, researchers of Pangang have carried experiments of improving $\mathrm{TiO}_{2}$ content in the slag by the way of mining process, and some other people want to produce Ti-Si alloy by this kind of titanium slag.

\section{Problem of High Cost and Low Productivity of Direct Reduction Process}

As we all know, for iron and steel enterprises, only the production capacity reaches to certain scale the economy benefits will come into being. Take a RHF direction reduction plant with capacity of 0.15 million tons of metallized pellets as an example, the depreciation discharge exceeds 75 yuan for each ton metallized pellet when the depreciation time is 12 years, that is a high value and has no competition advantage comparing with the normal iron making process.

For the vanadium bearing titanomagnetite, fully using the titanium element is the essence of comprehensive utilizing magnetite resources. Only when the production reaches to certain scale the cost drops and the beneficial results of titanium products come into being at the same time, at this base, the benefits of comprehensive utilizing of vanadium bearing titanomagnetite can be realized.

At present, facilities as rotary kiln and RHF have not the production scale superiority [4], maybe the shaft furnace is a better choice for direct reduction.

\section{Conclusions}

The direct reduction in RHF-melting and deep reduction in EAF process is feasible and the recovery rate of $\mathrm{Fe}, \mathrm{V}$, and Ti reach to $89 \%, 45 \%$, and $72 \%$ respectively.

There are some restrictive problems existing in the real production that have not been solved such as short life span of the EAF lining, low recovery rate of the heat, how to use titanium slag efficiently etc., and we need to overcome them and put this process into large scale production. 
At present, personally think that taking research and experiments on the shaft furnace direct reduction process can make good supplements for the RHF direct reduction process when disposing vanadium bearing titanomagnetite.

\section{References}

[1] Liu Hong, Yue-hua Ding, Hong-en Xie Prospect of Comprehensive Utilization of V-Bearing Titanomagnetite by Rotary Hearth Furnace Process [J].METALMINE, 2007,(5):10-13.

[2] Qing-qiang Weng, Jian-hua Zheng. Craft Analysis of Rotary Hearth Furnace Direct Return to Iron [J]. Industrial Furnace, 2012, 34(4):12-15.

[3] Hua-wen Xiong, Yan-de Dai. Meaning and Prospect of The Rotary Hearth Furnace Direct Reduction Technology to The Comprehensive Utilizing of Resource in Iron and Steel Industry [J].ENERGY OF CHINA,2012,34(2): 5-7, 13.

[4] Fei-hu Long. Research and Choice on The Two Direct Reduction Processes for Dealing With Vanadium Titanium Magnetite Resources in Pan-Xi Area. Sichuan Metallurgy,2011,33(5):1-4. 